\title{
The development and application of a new multifunction drift well gauge tool
}

\author{
Ke Wang ${ }^{1,}$ a * \\ ${ }^{1}$ Sinopec Northwest oil field branch NO.1 oil production plant \\ a553868188@qq.com
}

Keywords: Multifunction drift well gauge tool; Well depth check; Soft dip; Efficiency improvement; Cost saving

Abstract. Now Tahe oil field has reached the middle development stage and the improved wells in the oilfield are increasing gradually. Ahead of perforation change and running the perforation string, wiper trip, soft dip and wellbore depth check are necessary jobs. The new multifunction drift well gauge tool, combining the three jobs together, improved the working efficiency greatly and kept the operation safety.

\section{Introduction}

The casing drift well gauge tool is a thin Tubular tool to detect the casing size, which consists of joints and a barrel. The lower joint and cylinder is connected by treads. The lower cylinder can be thin. The purpose of processing the lower part of the cylinder into a thin wall is: when the casing inner diameter at the deformation point is smaller than the outer diameter of the casing drift well gauge tool, the cylinder can be easily deformed and the deformation condition can be known. At the same time, the impact force can be buffered and the casing drift well gauge tool is less likely to get stuck.

Well drifting operation is a job using drift well gauge tool. The purpose of well drifting is to know whether the downhole tools can be put into the downhole successfully. Well drifting operation can be divided into hard drifting and soft drifting. Oil tube or drilling pipe is used in the operation of hard drifting, and drift well gauge tool with larger diameter is used. The advantage of hard drifting is its good effect, but it takes too much time. Drift well gauge tool with smaller diameter is used in soft drifting. The advantage of soft drifting is that it can save time, but it is easily to get stuck.

The purpose of soft dip is to know about the artificial well bottom. At the same time, it can save time and money.

Casing depth school is to measure $\mathrm{GR}+\mathrm{CCL}+\mathrm{MMD}$ curve on the condition of empty wellbore. If there is radioactive contamination in old wells, the GR+CCL curve may not be detected at the deep depth, which will cause the failure of the measurement. Before the tripping in, the GR+CCL+MMD curve is both measured in casing depth school and pipe depth school operation. Even though the GR curve cannot be detected because of contamination, the depth can be determined using the twice magnetic mark.

Sand reservoir is one of the main reservoir in Tahe Oilfield. The reservoir and structural condition are very complex, because the reservoir has experienced long tectonic movement. Compared with sand reservoir in Middle East and east China, most reservoir is deeper than 4000m, and high reservoir temperature, high pressure, high viscosity and high salinity increased the difficulty of developing the reservoir. The pressure of Ordovician formation is high and the production is high, but the formation leakage is serious. Well killing of some wells is difficult, and well killing fluid balance window appears small. So the combination of well drifting, soft dip and casing depth school can save much time and money. 


\section{Structure and theory}

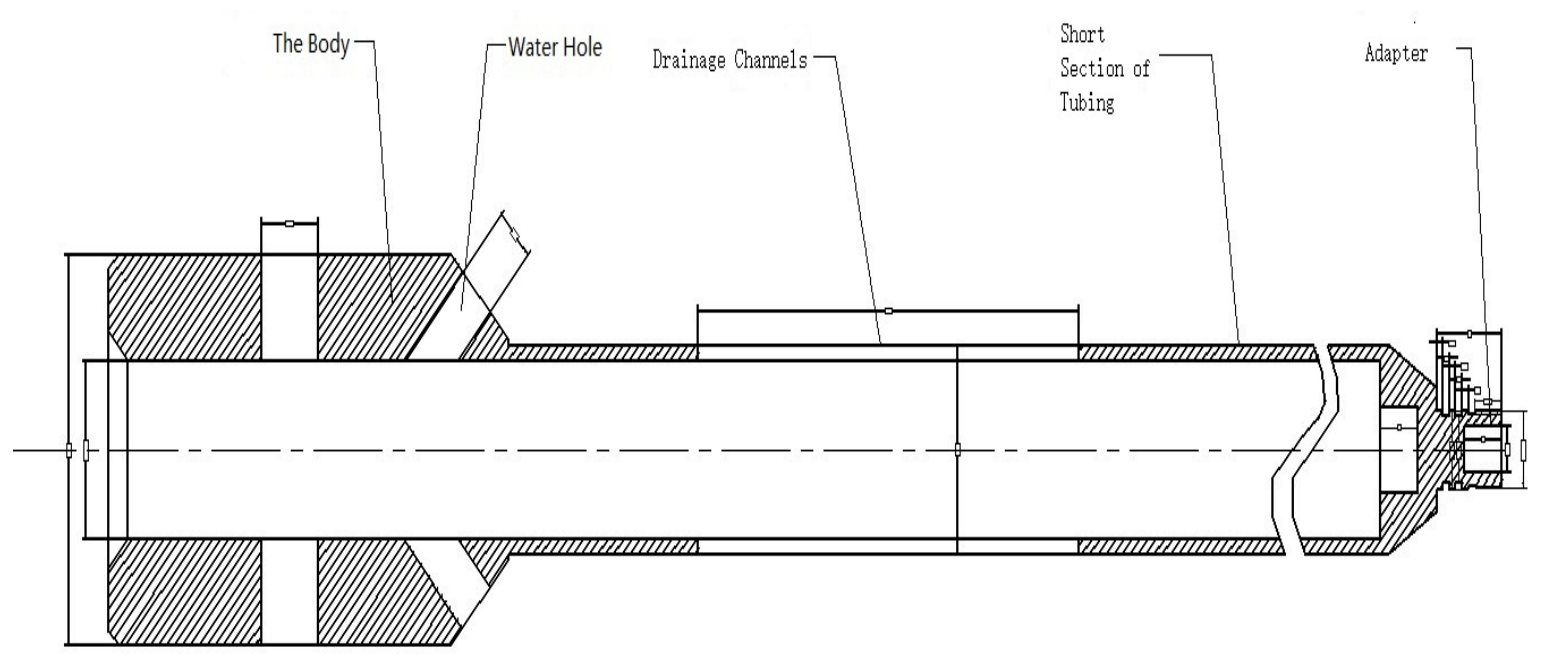

Fig1: Constructure of multifunction drift well gauge tool

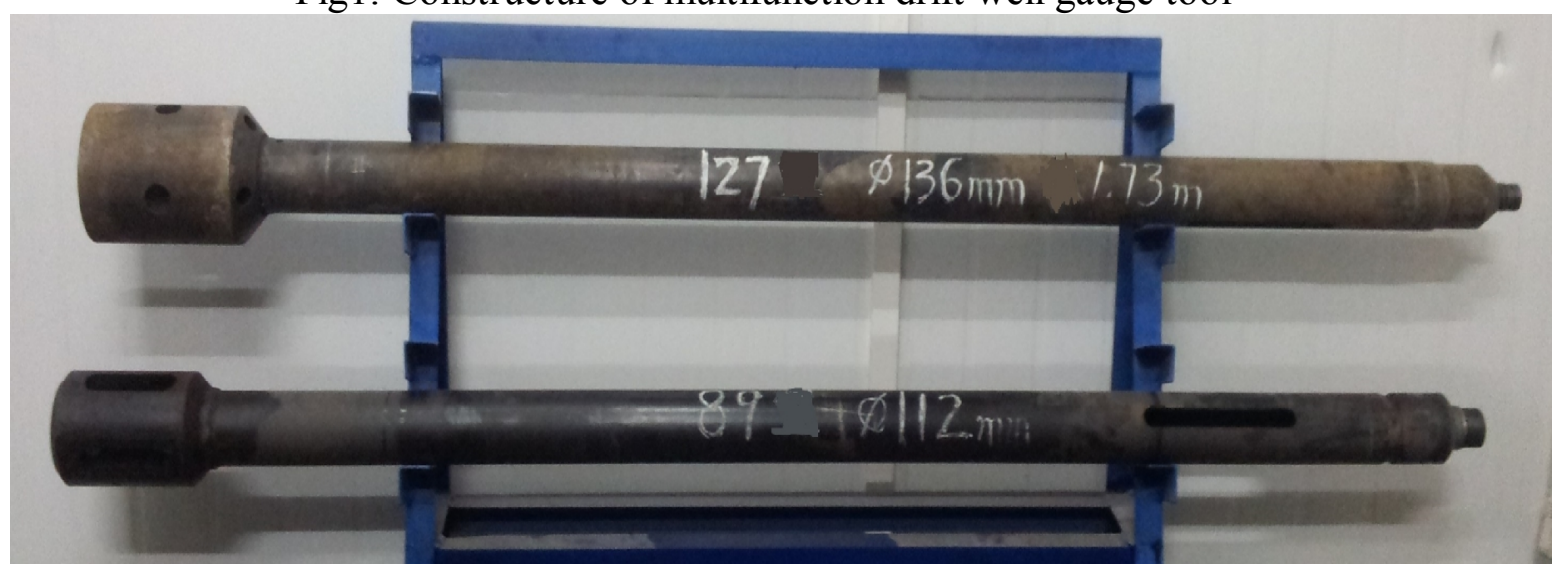

Fig2: The picture of type 127 and type 89 drift well gauge tool

The structure of multifunction drift well gauge tool is shown in Fig1. The physical picture of multifunction drift well gauge tool is shown in Fig2. The multifunction drift well gauge tool consists of adapters, a short section of tubing, the body, drainage channels and water hole. The body of the gauge tool and the short section of tubing are welded together. The speed of putting down the multifunctional drift well gauge tool is controlled below $4000 \mathrm{~m} / \mathrm{h}$. At present, the size of the gauge is shown in Tab1.

Tab1: Size of multifunctional drift well gauge tool

\begin{tabular}{|c|c|c|}
\hline Size of perforating gun & Length of drifting gauge & Diameter of drifting gauge \\
\hline $127 \mathrm{~mm}$ & $1.73 \mathrm{~m}$ & $136 \mathrm{~mm}$ \\
\hline $89 \mathrm{~mm}$ & $1.73 \mathrm{~m}$ & $112 \mathrm{~mm}$ \\
\hline
\end{tabular}

Adapter can be connected with cable perforation leading horse and natural gamma-magnetic positioning combination logging tool. The use of short section of tubing is to meet tensile strength and impact resistance. The use of water hole and water discharge channel is to decrease the downstream flow resistance.

\section{Advantages}

Efficient and flexible: one trip to school the depth, have bottom dip and well drifting. Improve the efficiency. 
Safety: The use of welded structures do not appear falling objects caused by tripping. The use of 73 $\mathrm{mm}$ tubing as the body is easy for salvage. At the same time the reducing number of well trips also reduces the risk.

Handiness : Reducing the weight of multifunction drift well gauge tool by adding water hole and drainage channels without sacrificing mechanical properties.

If the trip is blocked, the blocking location can be located accurate. So the problem can be easily solved.

The statics of drifting gauge application in Tahe oilfield in 2013 is shown in Tab2.

Tab2: Statics of drifting gauge application in Tahe oilfield in 2013

\begin{tabular}{|r|l|l|c|c|}
\hline No. & time & Well number & Perforation interval & Use condition \\
\hline 1 & $2013-4-19$ & T452 & $4524-4527$ & well \\
\hline 2 & $2013-5-13$ & TK7228X & $4432-4433.5$ & well \\
\hline 3 & $2013-6-3$ & TK936 & $4594-4596$ & well \\
\hline 4 & $2013-6-13$ & S47 & $5414-5418$ & well \\
\hline 5 & $2013-7-4$ & TK477 & $5101-5105$ & well \\
\hline 6 & $2013-7-22$ & TK260 & $4534-4537$ & well \\
\hline 7 & $2013-7-28$ & AT23X & $4170-4172$ & well \\
\hline 8 & $2013-8-11$ & TK269 & $5548.0-5552.0$ & well \\
\hline 9 & $2013-8-15$ & S1072-1CX & $5246.5-5249$ & well \\
\hline 10 & $2013-9-1$ & TK7208 & $4420-4421.5$ & well \\
\hline
\end{tabular}

The objective of well repairmen of S1072-1CX is:

(1) Block the production layer C1K1: 5273-5276m;

(2) Test layer by layer, perforation in C1K1: 5246.5-5249m.

Operation safety requirements: due to the hydrogen sulfide containment in the well and the high production $16254 \mathrm{~m} 3 / \mathrm{d}$, the degassing operation must be completed fully. Care about safety.

\section{Conclusion}

The successful application of this multifunction drift well gauge tool saved a lot time and money for perforation completion operation. At the same time, this tool can be used repeatedly, so this tool is worthy of popularization. Nowadays, the amount of work about perforation change accounted for about $30 \%$. With the development of oilfield the amount of measured wells is increasing. So the large-scale application of this technology will provide a new idea of improve efficiency and reduce the cost. The new multifunction drift well gauge tool, combining the three jobs together, improved the working efficiency greatly and kept the operation safety.

\section{References}

[1] Sinopec oil and gas Wells well control management stipulation. China Sinopec An [2011]097 in Chinese

[2] Li, X.Z. Li, J.X. Yang, L.N. The design and application of Multifunction drifting gauge Oil Field Equipment 2007,36 ( 1 ) 71-72 ; in Chinese

[3] Wang, H.T. Chen D.J. Wan, L.X. Soft flux process Inner Mongolia Petrochemical Industry. 2009,17 ( 20 ) ,25-26 ; in Chinese 
[4] Shi, C.C. The development and application of integrating drifting gauge. 2012,01 ( 33 ) , 4-6.In Chinese

[5]Ozkan, E., Sarica, C., Haci, Marc., "Influence of pressure drop along the wellbore on horizontal-well productivity"SPEJ, Vol.4(3), Sept.1999 pp 288-301

[6]Brekke, K., Lien, S.C., "New, simple completion method for horizontal wells improve production performance in high permeability thin oil zones. SPE Drilling and Completion, Sept. 1994, 205-209 